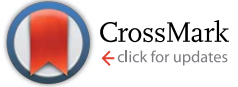

Cite this: RSC Adv., 2017, 7, 16092

Received 11th December 2016 Accepted 6th March 2017

DOI: $10.1039 / c 6 r a 28035 h$

rsc.li/rsc-advances

\section{Comparison of the removal and adsorption mechanisms of cadmium and lead from aqueous solution by activated carbons prepared from Typha angustifolia and Salix matsudana}

\author{
Chunfang Tang, ${ }^{\text {*a }}$ Yan Shu, ${ }^{a}$ Riqing Zhang, ${ }^{\mathrm{b}}$ Xin Li, ${ }^{\mathrm{c}}$ Jinfeng Song, ${ }^{a}$ Bing $\mathrm{Li}{ }^{a}$ \\ Yuting Zhang ${ }^{a}$ and Danling $\mathrm{Ou}^{\mathrm{a}}$
}

\begin{abstract}
Activated carbon adsorption is a promising technique for treatment of low-concentration heavy metal pollutants with high efficiency, simple operation, and flexibility; however, the cost of commercial activated carbon is too high. Therefore, much attention has been paid to activated carbon derived from low-cost agricultural and forest wastes. In this work, adsorption of $\mathrm{Cd}$ and $\mathrm{Pb}$ in aqueous solutions were conducted through batch experiments using Typha angustifolia carbon (TC) and Salix matsudana carbon (SC) prepared by phosphoric acid activation, and the adsorbents were characterized using SEM, FTIR, XPS, elemental analyzer, BET surface area, and zeta potential measurements. Both TC and SC mainly encompassed mesopores and bonds of $\mathrm{O}-\mathrm{H}, \mathrm{C}-\mathrm{O}, \mathrm{C}=\mathrm{O}$, and $\mathrm{P}=\mathrm{O} / \mathrm{P}-\mathrm{O}-\mathrm{C}$. The BET surface area and isoelectric point $\left(\mathrm{pH}_{\mathrm{IEP}}\right.$ ) of TC and SC was 130.42 and $234.42 \mathrm{~m}^{2} \mathrm{~g}^{-1}$ and 3.45 and 4.38 , respectively. The adsorption capacity of $\mathrm{Cd}$ and $\mathrm{Pb}$ for $\mathrm{TC}$ and $\mathrm{SC}$ both relied positively on the $\mathrm{pH}$ and humic acid but negatively on $\mathrm{NaCl}$ in the media. The adsorption process was spontaneous and endothermic, involved physicochemical reactions, and fitted well with the pseudo second-order and Langmuir models. Both the intraparticle diffusion and the chemical reaction were the rate limiting steps during adsorption. The maximum sorption capacity of $\mathrm{Cd}$ and $\mathrm{Pb}$ was 48.08 and $61.73 \mathrm{mg} \mathrm{g}^{-1}$ (TC) and 40.98 and $58.82 \mathrm{mg} \mathrm{g}^{-1}$ (SC), respectively, at $\mathrm{pH} 5$ and $25{ }^{\circ} \mathrm{C}$. The adsorption-desorption results showed that both activated carbons had good regeneration and reusability properties. The results suggested that both TC and SC had potential applications in the removal of $\mathrm{Cd}$ and $\mathrm{Pb}$ from aqueous solutions.
\end{abstract}

\section{Introduction}

Heavy metal pollution can result in great environmental issues due to their persistence and toxicity, among which $\mathrm{Cd}$ and $\mathrm{Pb}$ are coexistent, human carcinogenic, and should be paid more attention. ${ }^{\mathbf{1 , 2}}$ Physical and chemical methods are commonly used to remove heavy metals from wastewater. ${ }^{3,4}$ However, the cost of these methods such as ion exchange, membrane separation, electroanalysis, and air floatation are expensive and sometimes unsuitable for the treatment of low-level metal pollutants. ${ }^{5-7}$ Adsorption methods provide the advantages of low cost, simple operation, and low secondary environmental pollution, and can also be used to remove heavy metal pollutants at less than $100 \mathrm{mg} \mathrm{L}^{-1}$, when other methods cannot work effectively. ${ }^{8}$

${ }^{a}$ College of Environmental Science and Engineering, Central South University of Forestry and Technology, Changsha 410004, China. E-mail: cshntcf@163.com; Fax: +86731 85623372; Tel: +8613975116986

${ }^{b}$ College of Forestry, Central South University of Forestry and Technology, Changsha 410004, China

${ }^{c}$ College of Environmental Science and Engineering, Hunan University, Changsha 410082, China
Activated carbon is the most widely used adsorbent currently, but the price of commercial activated carbon produced from coal and wood raw materials is very high, which limits its application, especially in countries lacking these resources. Thus, currently the activated carbons prepared from agricultural and forestry residues have received increasing attention. ${ }^{9-13}$ The adsorption capacity of activated carbon depends on its raw materials and preparation methods. Chemical activation has a lower energy consumption and higher productivity than physical activation. Usually $\mathrm{H}_{3} \mathrm{PO}_{4}$ is used as an activator due to lower environmental toxicity than $\mathrm{ZnCl}_{2}$ and a lower activated temperature than $\mathrm{KOH} .^{9,13}$

Cattails are perennial, herbage plants with a high adaptability and large biomass. They are widely used in constructed wetland for removing nitrogen, phosphorous, and organics from wastewater. ${ }^{\mathbf{1 4}}$ However, casually discarding the withered aerial part of cattails will not only waste resources but also cause the eutrophication of water and swamping of lakes. Researchers have proved that cattail-based activated carbon has a good adsorption ability on some organics, ${ }^{15}$ as well as the advantages of rich resource, low cost, waste recycling, resource saving, and 
environment friendliness. ${ }^{9-13}$ Among which, Typha angustifolia provides not only a high biomass and but also pore structure due to its vascular property. Willow plants like Salix matsudana possess many advantages for manufacturing activated carbon including various species, easy reproduction, fast growth, high biomass, and tolerance to adverse environments. ${ }^{16}$ Therefore, both $T$. angustifolia and $S$. matsudana are potential low cost materials for preparing activated carbon and were comprehensively discussed to exploit their new application for environmental protection in this paper.

Overall, to obtain cost-effective activated carbon requires more research including optimizing activating and adsorption conditions. Based on the pre-experiments of the adsorption of $\mathrm{Cd}$ and $\mathrm{Pb}$ with activated carbons prepared from T. augustifolia and $S$. matsudana impregnated by $\mathrm{H}_{3} \mathrm{PO}_{4}$, $\mathrm{HNO}_{3}$, and $\mathrm{KOH}, \mathrm{H}_{3} \mathrm{PO}_{4}$ was chosen for the preparation of $T$. augustifolia and S. matsudana carbons (TC and SC). The TC and SC are presumed to have encompassed phosphoric acid functional group and efficiently adsorbed $\mathrm{Cd}$ and $\mathrm{Pb}$ from aqueous solution. In a quest for a promising cattail and willow carbons, this study aimed to prepare a low cost TC and $\mathrm{WC}$, evaluate their sorption properties for $\mathrm{Cd}$ and $\mathrm{Pb}$, and physicochemically characterize TC and WC before and/or after adsorption experiments.

\section{Materials and methods}

\subsection{Preparation of carbons}

The withered aerial part of T. angustifolia and branches of $S$. matsudana were sampled from Yanghu Wetland in Changsha and non-flooding area of Dongting Lake in Yueyang, China, respectively. Cleaned cattail samples were dried at $80{ }^{\circ} \mathrm{C}$ to a constant weight and grounded with a micro-crusher (FZ102, Taisite, Tianjing). Sawdust of cleaned willow branches was also dried to a constant weight. After screened with a 60 mesh sieve, both samples were kept in sealed plastic bags individually for preparing carbons.

$10.0000 \mathrm{~g}$ of samples were first pre-incubated with $30 \mathrm{~mL}$ of $40 \%(\mathrm{v} / \mathrm{v}) \mathrm{H}_{3} \mathrm{PO}_{4}$ for $12 \mathrm{~h}$ in a series of $200 \mathrm{~mL}$ porcelain crucibles wrapped with a foil, then carbonized at $200{ }^{\circ} \mathrm{C}$ for $0.5 \mathrm{~h}$ and activated at $450{ }^{\circ} \mathrm{C}$ for $1 \mathrm{~h}$ in a muffle. After natural cooling, all carbons were washed several times with deionized water until the $\mathrm{pH}$ turned to 6-7; then dried at $105{ }^{\circ} \mathrm{C}$ for $24 \mathrm{~h}$, polished, and sieved through a 100 mesh (particle size < $150 \mathrm{~mm})$.

\subsection{Analysis of physical-chemical characteristics of carbons}

The physical and chemical properties of carbons were characterized by scanning electron microscopy (SEM) (QUANTA 450, China), Fourier transform infrared spectrophotometry (FTIR) (Shimadzu IRAffinity-1, Japan), automatic surface area and pore size analysis (Quadrasorb SI-3MP, America), zeta potential analysis (Nano ZS ZEN3600, Britain), and X-ray photoelectron spectroscopy (XPS) (K-Alpha, America), respectively. The elemental compositions of both activated carbons were analyzed with elemental analyzer (Elementar, Germany).

\subsection{Adsorption experiments}

A series of $250 \mathrm{~mL}$ flasks containing $50 \mathrm{~mL}$ solution of $\mathrm{Cd}$ and $\mathrm{Pb}$ with a given level (40-200 $\mathrm{mg} \mathrm{L}^{-1}$ ) and initial $\mathrm{pH}(3-8)$ were added a given dose of TC and SC (0.02-2 g), and shaken at a given temperature $\left(15-40{ }^{\circ} \mathrm{C}\right)$ and time $(2-120 \mathrm{~min})$ in a vibrator. $\mathrm{NaCl}\left(0.01-0.50 \mathrm{~mol} \mathrm{~L}^{-1}\right)$ and humic acid (HA) (5$\left.25 \mathrm{mg} \mathrm{L}^{-1}\right)$ were used as competitive ion and dissolved organic compound, respectively, for studying their effects on the adsorption of $\mathrm{Cd}$ and $\mathrm{Pb}$. Commercial activated carbon (CAC) was used as a reference to compare the maximum adsorption capacity. Except the tests of parameter effects on the adsorption, the adsorption time, initial $\mathrm{pH}$ value, temperature, initial metal ion concentration, dose of carbons in solutions, and vibrating rate were $60 \mathrm{~min}, 5,25{ }^{\circ} \mathrm{C}, 50 \mathrm{mg} \mathrm{L}{ }^{-1}, 0.1000 \mathrm{~g}(2 \mathrm{~g}$ $\mathrm{L}^{-1}$ ), and $180 \mathrm{rpm}$, respectively. The initial values of $\mathrm{pH}$ in solutions were adjusted with $0.1 \mathrm{~mol} \mathrm{~L}^{-1}$ solution of $\mathrm{HCl}$ and $\mathrm{NaOH}$. The levels of $\mathrm{Cd}$ and $\mathrm{Pb}$ in filtrate after adsorption were analyzed by atom adsorption spectrometer (AAnalyst 300, Perkin-Elmer, Germany).

\subsection{Adsorption and desorption cycles}

The desorption conditions for $\mathrm{Cd}$ and $\mathrm{Pb}$ were similar to those of adsorption studies. $0.1 \mathrm{~g}$ of TC or SC was treated with $50 \mathrm{~mL}$ solution containing $50 \mathrm{mg} \mathrm{L}^{-1}$ of $\mathrm{Cd}$ or $\mathrm{Pb}(\mathrm{pH} 5)$. The solution was centrifuged after $60 \mathrm{~min}$ adsorption. The spent TC or SC was resuspended in $50 \mathrm{~mL}$ of $1.0 \mathrm{~mol} \mathrm{~L}^{-1} \mathrm{HCl}$ for $12 \mathrm{~h}$. After centrifugal separation the TC or SC was washed several times with deionized water in order to completely remove $\mathrm{Cl}^{-}$, and then reused to adsorb $50 \mathrm{mg} \mathrm{L}^{-1} \mathrm{Cd}$ and $\mathrm{Pb}$ in $50 \mathrm{~mL}$ solution. The above procedure was repeated four times using the same method, and all the levels of $\mathrm{Cd}$ and $\mathrm{Pb}$ in the supernate after centrifugation were measured.

\subsection{Statistics and analysis of data}

The results were the means of two duplicate tests.

The adsorption capacity $\left(\mathrm{mg} \mathrm{g}^{-1}\right)$ and removal efficiency (\%) were figured by formulas (1) and (2), respectively:

$$
\begin{gathered}
q_{t}=\frac{\left(C_{0}-C_{t}\right) V}{M} \\
R=\frac{\left(C_{0}-C_{t}\right)}{C_{0}} \times 100 \%
\end{gathered}
$$

where $q_{t}\left(\mathrm{mg} \mathrm{g}^{-1}\right)$ is the quantity of adsorbate adsorbed on adsorbent at time of $t ; C_{0}$ and $C_{t}\left(\mathrm{mg} \mathrm{L}^{-1}\right)$ are the levels of adsorbate in solution at initial and $t$ time, respectively; $M(\mathrm{~g})$ is the dose of adsorbent; $V(\mathrm{~L})$ is the volume of solution.

Gibbs eqn (3)-(5) of changes of standard free energy $\left(\Delta G^{0}, \mathrm{~kJ}\right.$ $\left.\mathrm{mol}^{-1}\right)$, enthalpy $\left(\Delta H^{0}, \mathrm{~kJ} \mathrm{~mol}^{-1}\right)$, and entropy $\left(\Delta S^{0}, \mathrm{~J} \mathrm{~mol}^{-1}\right.$ $\mathrm{K}^{-1}$ ) were used to analyze adsorption thermodynamics:

$$
\Delta G^{0}=-R T \ln K_{\mathrm{c}}
$$

where $R$ is a gas constant, $8.314 \mathrm{~J} \mathrm{~mol}^{-1} \mathrm{~K}^{-1} ; T(\mathrm{~K})$ is an absolute temperature; $K_{\mathrm{c}}$ is an equilibrium constant and was calculated by formula (4): 


$$
K_{\mathrm{c}}=\frac{C_{\mathrm{ae}}}{C_{\mathrm{e}}}
$$

where $C_{\mathrm{ae}}$ and $C_{\mathrm{e}}\left(\mathrm{mg} \mathrm{L}^{-1}\right)$ are adsorbate levels in adsorbent and solution at adsorption equilibrium, respectively.

$$
\ln K_{\mathrm{c}}=\frac{\Delta S^{0}}{R}-\frac{\Delta H^{0}}{R T}
$$

Adsorption isotherms were assayed by Langmuir (6) and Freundlich (7) models, and adsorption feasibility was judged by formula (8):

$$
\begin{aligned}
\frac{C_{\mathrm{e}}}{q_{\mathrm{e}}} & =\frac{1}{K_{\mathrm{a}} Q_{\mathrm{m}}}+\frac{1}{Q_{\mathrm{m}}} C_{\mathrm{e}} \\
\log q_{\mathrm{e}} & =\log K_{\mathrm{F}}+\frac{1}{n} \log C_{\mathrm{e}} \\
R_{\mathrm{L}} & =1 /\left(1+K_{\mathrm{a}} C_{0}\right)
\end{aligned}
$$

where $q_{\mathrm{e}}\left(\mathrm{mg} \mathrm{g}^{-1}\right)$ is an equilibrium adsorption capacity; $Q_{\mathrm{m}}$ $\left(\mathrm{mg} \mathrm{g}^{-1}\right)$ is a Langmuir monolayer maximum adsorption capacity; $K_{\mathrm{a}}\left(\mathrm{L} \mathrm{mg}^{-1}\right)$ is an affinity or combining constant representing adsorption energy; $R_{\mathrm{L}}$ is a separating factor, a nondimensional constant; $K_{\mathrm{F}}\left(\mathrm{mg} \mathrm{g}^{-1}\right)$ is a Freundlich constant of adsorption capacity; $n$ is the energy of adsorption site or an adsorption intensity constant.

Equations of pseudo-first (9) and pseudo-second order (10) were used to evaluated adsorption kinetics:

$$
\begin{gathered}
\ln \left(q_{\mathrm{e}}-q_{t}\right)=\ln q_{\mathrm{e}}+k_{1} t \\
\frac{t}{q_{t}}=\frac{1}{k_{2} q_{\mathrm{e}}^{2}}+\frac{t}{q_{\mathrm{e}}}
\end{gathered}
$$

where $k_{1}\left(\min ^{-1}\right)$ and $k_{2}\left(\mathrm{~g} \mathrm{mg}^{-1} \mathrm{~min}^{-1}\right)$ are pseudo-first and pseudo-second order kinetics constants, respectively; others are the same as above.

Diffusion mechanism was analyzed with models of liquid film diffusion (11) and intra-particle diffusion (12), respectively:

$$
\begin{gathered}
\ln \left(\frac{C_{t}}{C_{0}}-\frac{1}{1+m K_{\mathrm{a}}}\right)=\ln \left(\frac{m K_{\mathrm{a}}}{1+m K_{\mathrm{a}}}\right)-\left(\frac{1+m K_{\mathrm{a}}}{m K_{\mathrm{a}}}\right) \beta_{\mathrm{L}} S_{\mathrm{s}} t \\
q_{t}=k_{\mathrm{id}} t^{1 / 2}+C
\end{gathered}
$$

where $m\left(\mathrm{~g} \mathrm{~L}^{-1}\right)$ is the level of adsorbate; $S_{\mathrm{s}}\left(\mathrm{cm}^{2}\right)$ is the surface area of adsorbent; $\beta_{\mathrm{L}}\left(\mathrm{cm} \mathrm{s}^{-1}\right)$ is the coefficient of film diffusion; $k_{\text {id }}\left(\mathrm{mg} \mathrm{g}^{-1} \min ^{-1 / 2}\right)$ is the rate constant of adsorption capacity; $C$ is a constant representing the thick of film or diffusion resistance; other indexes are the same to the above.

\section{Results and discussion}

\subsection{Characterization of carbons}

The physicochemical characteristics of activated carbon are most important factors for adsorption capacity. Table 1 gives the compositions of $\mathrm{C}, \mathrm{H}, \mathrm{O}, \mathrm{N}$, and $\mathrm{P}$ of both activated carbons obtained from elemental analysis and XPS (data inside the
Table 1 Elemental analysis for Typha angustifolia activated carbon (TC) and Salix matsudana activated carbon (SC) including the XPS results in the parenthesis

\begin{tabular}{llllll}
\hline Carbon & $\mathrm{C}(\%)$ & $\mathrm{H}(\%)$ & $\mathrm{O}(\%)$ & $\mathrm{N}(\%)$ & $\mathrm{P}(\%)$ \\
\hline TC & $43.73(73.71)$ & 3.30 & $30.77(20.05)$ & $0.25(1.53)$ & $1.89(2.14)$ \\
SC & $72.89(89.51)$ & 3.21 & $14.76(8.60)$ & $0.05(0.24)$ & $1.12(1.65)$
\end{tabular}

parenthesis) except $\mathrm{H}$, which showed a similar trend. The composition difference was probably due to the different analysis mechanism. The XPS measures only a few atomic layers on the material surface, whereas the elemental analysis presents the average composition of the entire sample. The fraction of $\mathrm{O}$ in TC was higher than that of SC, but SC contained more $\mathrm{C}$ element. It was probably attributed to the fact that $T$. angustifolia is a vascular herbaceous plant whereas $S$. matsudana belongs to woody plants.

Both TC and SC mainly had mesopores, and their BET specific surface area, total pore volume, and average pore diameter were 130.42 and $234.42 \mathrm{~m}^{2} \mathrm{~g}^{-1}, 13.29$ and $24.36 \mathrm{~mL}$ $\mathrm{g}^{-1}$, and 4.14 and $3.45 \mathrm{~nm}$, respectively. The micro-morphology of two carbons is presented in Fig. 1. TC had an irregular cylindrical structure with a rough surface and uneven pores, while SC presented a rough surface with layered structure and fine granular. The physical characteristics of SC were better than those of TC, which helped more with the physical adsorption of $\mathrm{Cd}$ and $\mathrm{Pb}$.

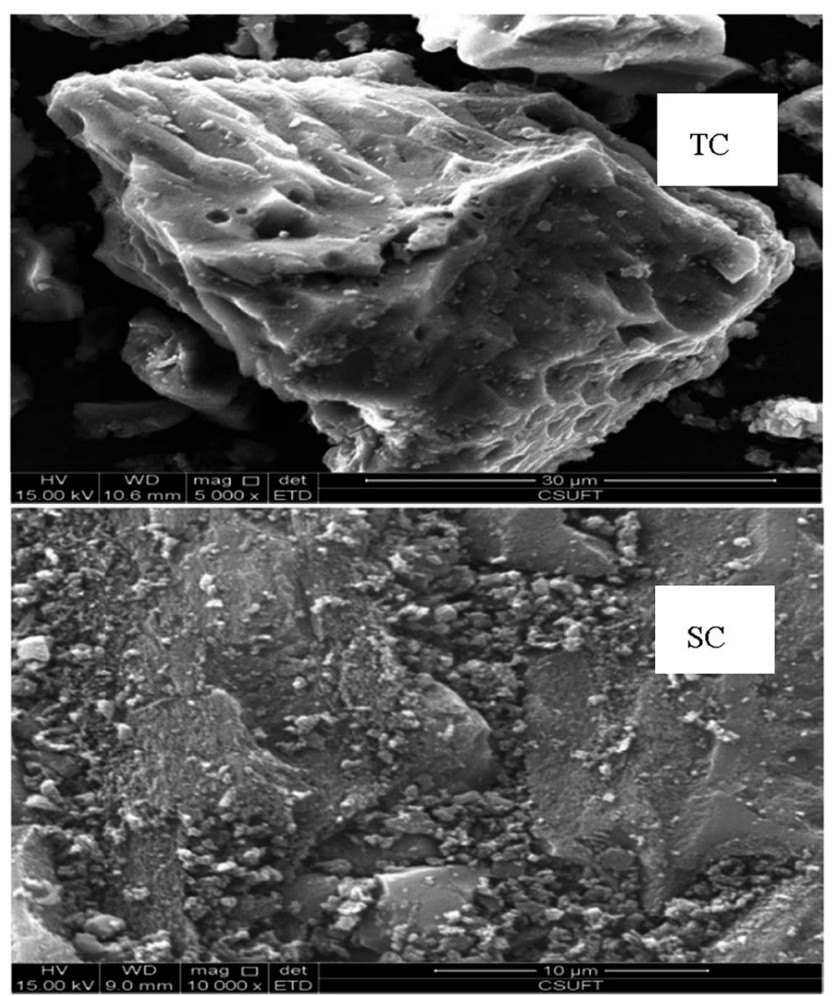

Fig. 1 SEM micrograph of Typha angustifolia activated carbon (TC) and Salix matsudana activated carbon (SC). 


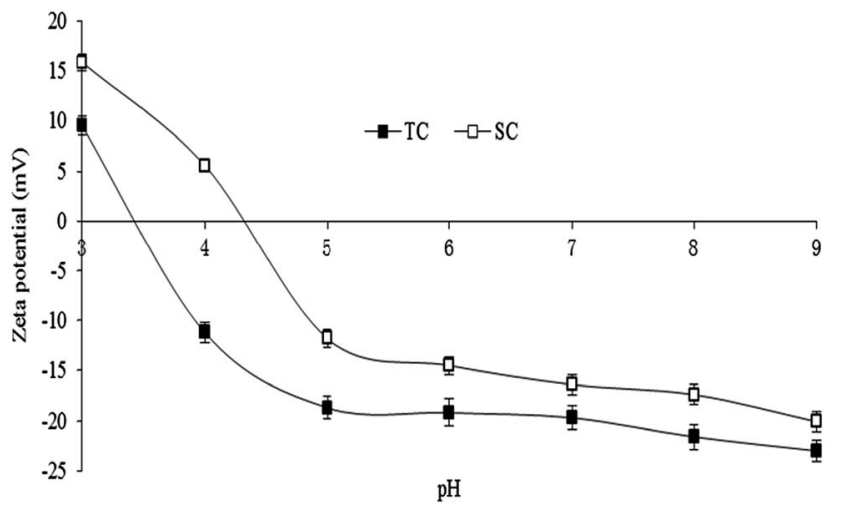

Fig. 2 Zeta potential of Typha angustifolia activated carbon (TC) and Salix matsudana activated carbon (SC). Error bar is the standard deviation of the mean.

The zeta potential of colloid particle is the potential difference between adsorptive and diffusive layers adhered on the solid surface in a liquid-solid system. The isoelectric point $\left(\mathrm{pH}_{\mathrm{IEP}}\right)$ of solid is the negative logarithm of potential ions, and is the $\mathrm{pH}$ value of solution when the zeta potential becomes zero and if $\mathrm{H}^{+}$ acts as a potential ion. The zeta potential of TC and SC declined from 9.57 to $23 \mathrm{mV}$ and 15.89 to $20.11 \mathrm{mV}$ when the solution $\mathrm{pH}$ increased from 3 to 9 , and their $\mathrm{pH}_{\mathrm{IEP}}$ values were 3.45 and 4.38 , respectively (Fig. 2). At the same solution $\mathrm{pH}$, the zeta potential and $\mathrm{pH}_{\mathrm{IEP}}$ of TC were smaller than those of SC. This was more helpful for the adsorption of $\mathrm{Cd}$ and $\mathrm{Pb}$ by ion exchange or electrostatic attraction and complexation when the initial solution $\mathrm{pH}$ was lower or higher than the $\mathrm{pH}_{\mathrm{IEP}}$, respectively.

As shown in Fig. 3, both TC and SC contained functional groups with oxygen. Among adsorption peaks of TC, the obvious broad peaks at bands of 3424 and $3183 \mathrm{~cm}^{-1}$ were attributed to the stretch vibration of hydroxyl $(\mathrm{O}-\mathrm{H})$; the peak at $1633 \mathrm{~cm}^{-1}$ was due to the stretch vibration of carbonyl $(\mathrm{C}=\mathrm{O})$. The peak at $1398 \mathrm{~cm}^{-1}$ was assigned to the stretch vibration of $\mathrm{C}-\mathrm{H}$ and also the intra-surface bending vibration of $\mathrm{C}-\mathrm{O}-\mathrm{H}$. The stretch vibration of $\mathrm{P}=\mathrm{O}$ caused an adsorption at $1072 \mathrm{~cm}^{-1}$. While in the FTIR spectrum of SC, $\mathrm{O}-\mathrm{H}$ resulted in an obvious broad adsorption peak at $3460 \mathrm{~cm}^{-1}$, and $\mathrm{C}-\mathrm{O}$ produced an absorption peak at $1355 \mathrm{~cm}^{-1}$; the adsorption peaks appearing at bands of 1650 and $1520 \mathrm{~cm}^{-1}$ were assigned to the stretch vibration of $\mathrm{C}=\mathrm{O}$, and $\mathrm{P}=\mathrm{O}$ and $\mathrm{P}-\mathrm{O}-\mathrm{C}$ produced an adsorption peak at $1080 \mathrm{~cm}^{-1}$.

The band shift and disappearance of some functional groups after the adsorption of $\mathrm{Cd}$ and $\mathrm{Pb}$ indicated that the corresponding groups participated in the adsorption to some extent. ${ }^{17,18}$ The peak area of oxygen containing groups of both carbons obviously decreased after the adsorption of $\mathrm{Pb}$, which probably resulted from the ion exchange between $\mathrm{Pb}^{2+}$ and $\mathrm{H}^{+}$ contained in $-\mathrm{OH},-\mathrm{COOH},-\mathrm{CHO}$, and the formation of complexes due to the electrostatic attraction between $\mathrm{Pb}^{2+}$ and deprotonation of $-\mathrm{OH} .{ }^{19}$ The absorption peak between 2000 and $2500 \mathrm{~cm}^{-1}$ was probably contributed to the release of $\mathrm{CO}_{2}$ during the analysis of infrared spectra. ${ }^{18}$ The areas of some adsorption peaks of TC were bigger than those of SC, suggesting that TC contained more functional groups which were more helpful to the chemical adsorption of $\mathrm{Cd}$ and $\mathrm{Pb}$.

The XPS is an effective approach to analyze the surface functional groups of adsorbents, and may provide more useful information on the adsorption mechanism than the FTIR, thermodynamics, and isotherms data. In the whole spectra of XPS (Fig. 4 TC-a and SC-a), the presence of P2p peaks suggested the successful modification of TC and $\mathrm{SC}$ by $\mathrm{H}_{3} \mathrm{PO}_{4}$. Cd2p and $\mathrm{Pb} 4 \mathrm{f}$ peaks appeared after their adsorption, which indicated that $\mathrm{Cd}$ and $\mathrm{Pb}$ were successfully adsorbed by TC and SC. The high revolution of the C1s spectra yielded peaks at approximately 284.72, 285.78 and 286.51, 288.79, and 291.41 and $292.86 \mathrm{eV}$, representing groups of $\mathrm{C}-\mathrm{C} / \mathrm{C}=\mathrm{C} / \mathrm{C}-\mathrm{H}, \mathrm{C}-\mathrm{O} / \mathrm{C}-\mathrm{OH}$, $\mathrm{C}=\mathrm{O}$, and $\mathrm{O}-\mathrm{C}=\mathrm{O}$, respectively (Fig. 4 TC-b); and peaks at 284.75 and $284.77,286.23,286.86,288.76$, and $291.34 \mathrm{eV}$ corresponded to $\mathrm{C}-\mathrm{C} / \mathrm{C}=\mathrm{C} / \mathrm{C}-\mathrm{H}, \mathrm{C}-\mathrm{O} / \mathrm{C}-\mathrm{OH}, \mathrm{C}-\mathrm{O}-\mathrm{C}, \mathrm{C}=\mathrm{O}$, and $\mathrm{O}-$ $\mathrm{C}=\mathrm{O}$, respectively (Fig. 4 SC-b). ${ }^{20}$ The $\mathrm{P} 2 \mathrm{p}$ peak contained two main peaks at 133.33 and $134.08 \mathrm{eV}$ (Fig. 4 TC-c) and 132.95 and $134.12 \mathrm{eV}$ (Fig. 4 SC-c), which was attributed to $\mathrm{P}=\mathrm{O}$ and $\mathrm{P}-\mathrm{O}-$ $\mathrm{C}$, respectively. The $\mathrm{P}$ atom in TC and SC mainly presented on the carbon surface by bonding to $\mathrm{O}$ atoms, which fitted well to the result of the FTIR analysis. ${ }^{21}$ Groups containing $\mathrm{O}$ played a key role on $\mathrm{Cd}$ and $\mathrm{Pb}$ adsorption. Before adsorption, the high resolution $01 \mathrm{~s}$ spectra contained three main peaks centered at 531.41, 533.01, and 536.05 eV (Fig. 4 TC-d) and 530.92, 532.75, and $536.53 \mathrm{eV}$ (Fig. 4 SC-d), which was attributed to groups of C$\mathrm{OH} / \mathrm{O}-\mathrm{H}, \mathrm{C}-\mathrm{O}-\mathrm{C}$, and -COOH, respectively. ${ }^{21}$ After sorption, the new peaks appeared at $530.31 \mathrm{eV}(\mathrm{C}=\mathrm{O}), 533.93,534.47 \mathrm{eV}$
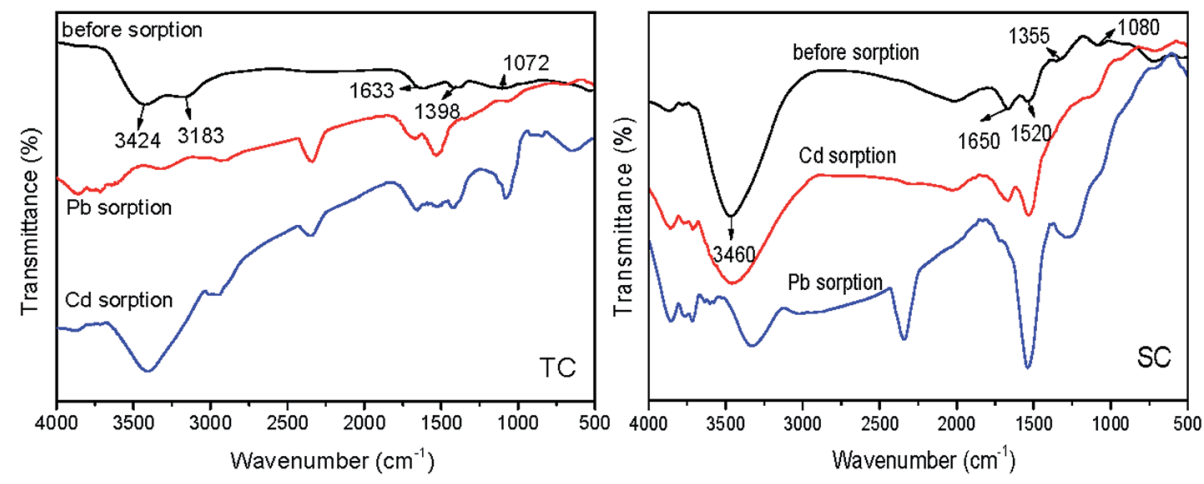

Fig. 3 FTIR spectrum of Typha angustifolia activated carbon (TC) and Salix matsudana activated carbon (SC). 

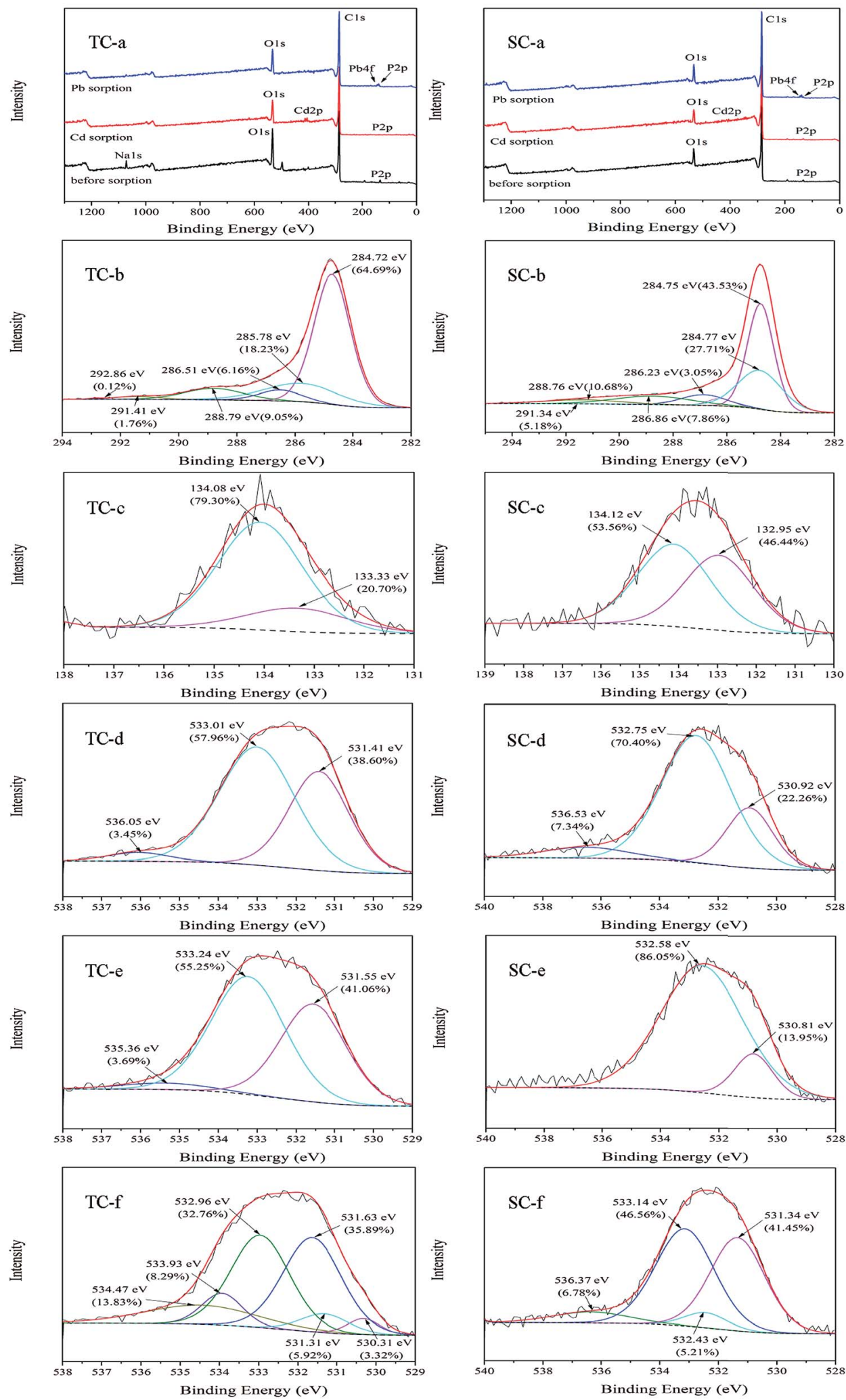

Fig. 4 X-ray photoelectron spectroscopy of Typha angustifolia activated carbon (TC) and Salix matsudana activated carbon (SC).

(-COOH) (Fig. 4 TC-f), $532.43 \mathrm{eV}(\mathrm{C}-\mathrm{OH})$, and $533.14 \mathrm{eV}(\mathrm{C}-\mathrm{O}-\mathrm{C})$ (Fig. 4 SC-f), which indicated their reactions with $\mathrm{Pb}$. The disappearance of peak at $536.53 \mathrm{eV}$ (Fig. 4 SC-e) and the shift of some peaks assigned to groups containing $\mathrm{O}$ (Fig. 4 TC-e and SC-e) also suggested the occurrence of adsorption reaction between TC and SC with $\mathrm{Cd}$ and $\mathrm{Pb}$. 


\subsection{Effect of contact time on adsorption and kinetics}

The study of adsorption kinetics can demonstrate the diffusion rate of adsorbate in solid-liquid adsorption systems, and help determine optimum parameters for the design of adsorption devices. The adsorption of $\mathrm{Cd}$ and $\mathrm{Pb}$ onto TC reached $95 \%$ of $q_{\mathrm{e}}$ in $2 \mathrm{~min}$, and $90 \%$ of $q_{\mathrm{e}}$ onto SC in $8 \mathrm{~min}$. After $10 \mathrm{~min}$ of contact, the adsorption of both ions by both carbons approached the value of $q_{\mathrm{e}}$ and tended to remain in a stable stage (Fig. 5a). There were more $\mathrm{Cd}$ and $\mathrm{Pb}$ adsorbed on $\mathrm{TC}$ than on $\mathrm{SC}$, but both had a similar adsorption equilibrium time, indicating a faster adsorption rate for TC than SC.

The adsorption process can be divided into three stages: film mass transfer, intraparticle diffusion, and chemical reaction on adsorbent. ${ }^{22}$ The concentration difference of adsorbate between adsorbent and solution is the main diffusion force of adsorbate. The initial rapid adsorption of $\mathrm{Cd}$ and $\mathrm{Pb}$ on TC and SC was due to rich adsorptive sites and large adsorption energy of carbons, large external diffusion rate of $\mathrm{Cd}$ and $\mathrm{Pb}$, and also a small diameter of $\mathrm{Cd}$ and $\mathrm{Pb}$ ions. ${ }^{23}$ The reason for the followed slow adsorption was attributed to adsorption transfer from extra diffusion to internal one, ${ }^{24}$ and the final saturated adsorption was due to the electrostatic repulsion between metal ions and adsorbent and thus restrict the function of the remaining activated sites. ${ }^{23}$

The normal pseudo-first and second order models were used in this work to describe adsorption kinetics. The values of $q_{\mathrm{e}}, k_{1}$, $k_{2}$, and $R^{2}$ calculated from the slopes and intercepts of fitted lines of adsorption data are shown in Table 2 . The values of $R_{1}{ }^{2}$ from the pseudo-first model ranked from 0.47 to 0.93 , and the values of $q_{1 \mathrm{e}, \mathrm{cal}}$ were far less than the corresponding values of $q_{\text {e,exp }}$. It indicated that the pseudo-first order equation could not describe the whole adsorption process, which was similar to the results in Ho et al. ${ }^{25}$ Although the pseudo-second order adsorption model could not definitely reflect the adsorption mechanism, it could fit well with heavy metal ion adsorption on most activated carbons, and had been widely used in the analysis of adsorption kinetics. ${ }^{23}$ The values of $R_{2}{ }^{2}$ based on pseudo-

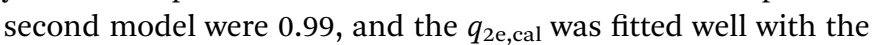
corresponding $q_{\mathrm{e} \text {,exp }}$. It suggested that the pseudo-second order model could describe the whole adsorption process of $\mathrm{Cd}$ and $\mathrm{Pb}$ on TC and SC; there were similar results in studies of Bouhamed $e t a .^{7}$ and Hamissa et $a l^{26}$

\subsection{Effect of initial solution $\mathrm{pH}$ on adsorption}

The initial solution $\mathrm{pH}$ is a key factor to determining adsorption capacity, and is greatly related to the surface charges and electricity of both adsorbent and adsorbate, including protonation or deprotonation of activated carbon and hydration, hydrolysis, and precipitation of metal ions..$^{22,24,27-29}$ With the increase of initial $\mathrm{pH}$ from 3 to 8, the adsorption capacity of $\mathrm{Cd}$ and $\mathrm{Pb}$ on TC increased from 15.91 and $16.93 \mathrm{mg} \mathrm{g}^{-1}$ to 20.02 and $24.01 \mathrm{mg} \mathrm{g}^{-1}$, and their removal efficiencies changed from 63.64 and $67.72 \%$ to 88.01 and $96.04 \%$, respectively. However, the Cd and $\mathrm{Pb}$ adsorption capacity on SC increased from 7.98 and $15.14 \mathrm{mg} \mathrm{g}^{-1}$ to 17.38 and $23.93 \mathrm{mg} \mathrm{g}^{-1}$, and their removal efficiency changed from 31.9 and $60.55 \%$ to 69.5 and $95.93 \%$, respectively (Fig. 5b).
When the initial solution $\mathrm{pH}$ is lower than the $\mathrm{pH}_{\mathrm{IEP}}$ of carbon, carbon will be positively charged, and the adsorption mainly includes physical adsorption and ion exchange. ${ }^{28}$ The adsorption of $\mathrm{Cd}$ and $\mathrm{Pb}$ was largely attributed to the ion exchange between $\mathrm{Cd}(\mathrm{OH})^{+}, \mathrm{Pb}^{2+}, \mathrm{Pb}(\mathrm{OH})^{+}, \mathrm{Pb}_{2} \mathrm{OH}^{3+}$, and $\mathrm{Pb}_{4}(\mathrm{OH})_{4}{ }^{4+}$ in solutions and $\mathrm{H}^{+}$on TC and SC, as well as between $\mathrm{H}^{+}$in solutions and the ions of $\mathrm{Cd}$ and $\mathrm{Pb}$ absorbed on both carbons. ${ }^{24,29}$ The repulsion of $\mathrm{Cd}$ and $\mathrm{Pb}$ ions between activated carbon and solution would also decrease their adsorption capacity.

The surface of TC and SC would be negatively charged when the initial $\mathrm{pH}$ in the solution was bigger than the $\mathrm{pH}_{\text {IEP }}$ of TC or $\mathrm{SC}$. Accordingly, the adsorption of $\mathrm{Cd}$ and $\mathrm{Pb}$ was mainly due to the electrostatic attraction between $\mathrm{Cd}^{2+}, \mathrm{Cd}(\mathrm{OH})^{+}, \mathrm{Pb}^{2+}$, $\mathrm{Pb}(\mathrm{OH})^{+}, \mathrm{Pb}_{2} \mathrm{OH}^{3+}$, and $\mathrm{Pb}_{4}(\mathrm{OH})_{4}{ }^{4+}$ and the negatively charged surface of TC and SC. With the increase of initial solution $\mathrm{pH}$, the level of $\mathrm{H}^{+}$in the solution decreased, and the competition adsorption between $\mathrm{H}^{+}$and the ions of $\mathrm{Cd}$ and $\mathrm{Pb}$ due to ion exchange also decreased. Furthermore, the net negative charge on the surface of TC and SC went up with the increase of $\mathrm{pH}$ in the solution, revealing that adsorption sites combined with cations increased, and thus there was an increase in the adsorption of $\mathrm{Cd}$ and $\mathrm{Pb}$. The precipitation of $\mathrm{Cd}$ and $\mathrm{Pb}$ on the surface of carbons including the combination of phosphate group with $\mathrm{Cd}$ and $\mathrm{Pb}$ on the carbon surface also caused an increase in their adsorption capacity.

The adsorption capacity of $\mathrm{Pb}$ was better than that of $\mathrm{Cd}$, especially when the initial solution $\mathrm{pH}$ was more than 6 , which was probably attributed to the stronger electrostatic attraction and ion exchange between $\mathrm{Pb}$ and $\mathrm{TC}$ and SC. This was also contributed to the combination between the large amount of $\mathrm{Pb}$ precipitation and TC and SC by the hydrogen bond. ${ }^{24,30}$ However, only a few $\mathrm{Cd}$ deposited until $\mathrm{pH}$ value reached to 8 , and $\mathrm{Cd}$ sinked completely at $\mathrm{pH}$ value of 11 in the solution. ${ }^{31}$ Compared to $\mathrm{SC}$, the adsorption capacity of $\mathrm{Cd}$ and $\mathrm{Pb}$ on $\mathrm{TC}$ was obviously higher, which was probably due to the lower $\mathrm{pH}_{\text {IEP }}$ of TC. The adsorption ability of activated carbon was so greatly dependent on the solution $\mathrm{pH}$ as to achieve better adsorption effectiveness and prevent precipitation of $\mathrm{Cd}$ and $\mathrm{Pb}$, the initial $\mathrm{pH}$ value in the solution was designated as 5 in the remaining experiments based on pre-adsorption experiments.

\subsection{Effect of dose of activated carbons on adsorption}

The removal efficiency of $\mathrm{Cd}$ and $\mathrm{Pb}$ from the solution significantly increased with the addition of both carbons from 0.02 to $2 \mathrm{~g}$. The removal rates for $\mathrm{Pb}$ by both carbons and $\mathrm{Cd}$ by TC were more than $90 \%$ at carbon dosage of $0.5 \mathrm{~g}$. On the other hand, the adsorption capacity of $\mathrm{Cd}$ and $\mathrm{Pb}$ on TC decreased from 54.38 and $61.19 \mathrm{mg} \mathrm{g}^{-1}$ to 1.20 and $1.23 \mathrm{mg} \mathrm{g}^{-1}$, and on SC declined from 29.25 and $54.50 \mathrm{mg} \mathrm{g}^{-1}$ to 1.13 and $1.22 \mathrm{mg} \mathrm{g}^{-1}$ (Fig. 5c).

The increase of removal efficiency of $\mathrm{Cd}$ and $\mathrm{Pb}$ with carbon dose resulted from the increase of total surface area and activated function groups on carbons. However, the removal did not reach $100 \%$, indicating that the competed adsorption of $\mathrm{Cd}$ and $\mathrm{Pb}$ between carbon and solution occurred, and the 

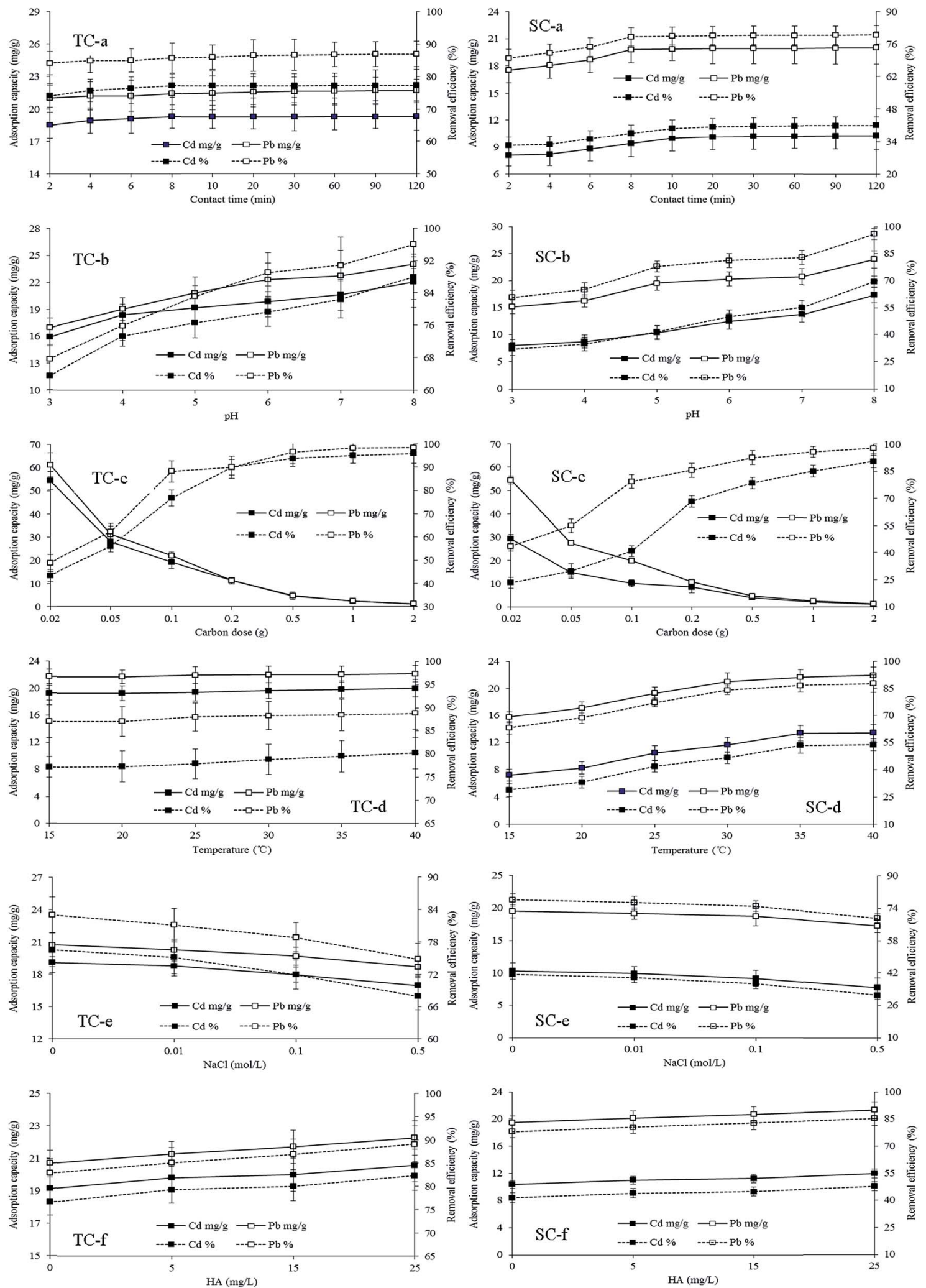

Fig. 5 Influence of initial solution $\mathrm{pH}$, time, activated carbon dose, temperature, $\mathrm{NaCl}$, and $\mathrm{HA}$ on the adsorption of $\mathrm{Cd}$ and $\mathrm{Pb}$ on $\mathrm{Typha}$ angustifolia activated carbon (TC) and Salix matsudana activated carbon (SC). Error bar is the standard deviation of the mean.

adsorption and desorption coexisted in the system. On the contrary, the obvious decrease of adsorption capacity of $\mathrm{Cd}$ and $\mathrm{Pb}$ with the dose of carbons could be explained by (1) at low levels of activated carbons in the solution, $\mathrm{Cd}$ and $\mathrm{Pb}$ ions had a relatively high content, and competed adsorption sites of carbons, and thus reached a high adsorption capacity; whereas, 
Table 2 Pseudo first-order and second-order adsorption parameters of Cd and Pb on Typha angustifolia activated carbon (TC) and Salix matsudana activated carbon (SC)

\begin{tabular}{|c|c|c|c|c|c|c|c|c|}
\hline Carbon & Ion & $\begin{array}{l}q_{\mathrm{e}, \exp } \\
\left(\mathrm{mg} \mathrm{g}^{-1}\right)\end{array}$ & $\begin{array}{l}q_{1 \mathrm{e}, \mathrm{cal}} \\
\left(\mathrm{mg} \mathrm{g}^{-1}\right)\end{array}$ & $\begin{array}{l}k_{1} \\
\left(\min ^{-1}\right)\end{array}$ & $R_{1}^{2}$ & $\begin{array}{l}q_{2 \mathrm{e}, \mathrm{cal}} \\
\left(\mathrm{mg} \mathrm{g}^{-1}\right)\end{array}$ & $\begin{array}{l}k_{2} \\
\left(\mathrm{~g} \mathrm{mg}^{-1} \min ^{-1}\right)\end{array}$ & $R_{2}{ }^{2}$ \\
\hline \multirow[t]{2}{*}{ TC } & $\mathrm{Cd}$ & 19.183 & 6.140 & 0.032 & 0.47 & 19.342 & 1.990 & 0.99 \\
\hline & $\mathrm{Pb}$ & 21.489 & 2.067 & 0.043 & 0.93 & 21.739 & 0.450 & 0.99 \\
\hline SC & $\mathrm{Cd}$ & 9.534 & 1.007 & 0.051 & 0.84 & 10.299 & 0.150 & 0.99 \\
\hline
\end{tabular}

at high doses of carbons, the adsorption of $\mathrm{Cd}$ and $\mathrm{Pb}$ did not reach saturation on carbons due to a rather low content of $\mathrm{Cd}$ and $\mathrm{Pb}$, or there were excess activated sites on carbons; (2) although the adsorptive sites for a given quality of carbon were constant, carbon particles would coagulate with each other with the increase of carbon content in a given volume of solution, causing the decrease of effective specific surface areas, and thus the increase of diffusion distance of adsorbates on the surface or inside carbons. ${ }^{30}$ Considering the removal efficiency and adsorption capacity together, $0.1000 \mathrm{~g}\left(2 \mathrm{~g} \mathrm{~L}^{-1}\right)$ of carbon was chosen for the rest experiments.

\subsection{Effect of initial temperature in solution on adsorption thermodynamics}

The increase of solution temperature increased the adsorption capacity of $\mathrm{Cd}$ and $\mathrm{Pb}$ on TC and SC (Fig. 5d), indicating that the adsorption process was endothermic, ${ }^{23}$ which was in accordance with $\Delta H^{0}>0$ (Table 3 ). The reasons were as follows: (1) the increased temperature increased the sites on the surface of carbons, decreased the thick of double electric layer of carbons, and thus the diffusion resistance of adsorbates to adsorbents; (2) the increased temperature helped to the dehydration for Cd and $\mathrm{Pb}$ ions, and the diameter of free ions is less than that of hydrated ones (the diameter of free ions of $\mathrm{Cd}$ is $0.97 \AA$, and $\mathrm{Pb}$ is $1.20 \AA$; hydrated ions of Cd $4.26 \AA$, Pb $4.01 \AA$ ). ${ }^{32}$ Therefore, free ions could be easily adsorbed by ion exchange and diffuse to the micropores of carbons, causing an increased adsorption capacity in a given volume pore. ${ }^{23}$

The adsorption of $\mathrm{Cd}$ and $\mathrm{Pb}$ on $\mathrm{SC}$ was more sensitive to temperature than on TC, indicating that chemical adsorption on SC needed more thermo and was less easier to occur than on TC. At an identical temperature, the adsorption capacity of $\mathrm{Pb}$ was higher than that of $\mathrm{Cd}$, indicating that more thermal energy or a higher temperature was needed for the same adsorption capacity of $\mathrm{Cd}$ as $\mathrm{Pb}$. An initial solution temperature of $25^{\circ} \mathrm{C}$ was chosen as an adsorption temperature for the rest of the experiments based on the non-obvious effects of temperature on adsorption.

Analysis of adsorption thermodynamics helps determine the values of $\Delta G^{0}, \Delta H^{0}$, and $\Delta S^{0}$, and thus the characteristics of adsorption. For the adsorption of $\mathrm{Cd}$ and $\mathrm{Pb}$ on $\mathrm{TC}$ and $\mathrm{Pb}$ on SC, the $\Delta G^{0}$ values were below zero and decreased with the increase of the temperature, revealing that the initiative and feasibility of adsorption increased with the temperature. ${ }^{33}$ That the values of $\Delta G^{0}$ of $\mathrm{Cd}$ adsorption on SC were bigger than zero did not mean that the adsorption was non-spontaneous, but rather this meant that an energy barrier existed during adsorption, and $\Delta G^{0}$ would drop below zero with the increase of temperature. However, the values of $\Delta G^{0}$ also depend on the models of thermodynamics chosen, which can turn a negative $\Delta G^{0}$ to a positive one. ${ }^{24}$ The $\Delta G^{0}$ values of TC less than those of $\mathrm{SC}$ revealed that the adsorption of $\mathrm{Cd}$ and $\mathrm{Pb}$ on TC was more spontaneous, feasible, and effective than that on TC. That the values of $\Delta G^{0}$ of $\mathrm{Pb}$ adsorption were lower than those of $\mathrm{Cd}$

Table 3 Thermodynamic parameters of $\mathrm{Cd}$ and $\mathrm{Pb}$ adsorption on Typha angustifolia activated carbon (TC) and Salix matsudana activated carbon (SC)

\begin{tabular}{|c|c|c|c|c|c|c|c|c|c|}
\hline \multirow[b]{2}{*}{ Ion } & \multirow[b]{2}{*}{$T(\mathrm{~K})$} & \multicolumn{2}{|l|}{$\underline{\ln K_{\mathrm{c}}}$} & \multicolumn{2}{|c|}{$\Delta G^{0}\left(\mathrm{~kJ} \mathrm{~mol}^{-1}\right)$} & \multicolumn{2}{|c|}{$\underline{\Delta H^{0}\left(\mathrm{~kJ} \mathrm{~mol}^{-1}\right)}$} & \multicolumn{2}{|c|}{$\Delta S^{0}\left(\mathrm{~J} \mathrm{~mol}^{-1} \mathrm{~K}^{-1}\right)$} \\
\hline & & $\mathrm{TC}$ & $\mathrm{SC}$ & TC & SC & TC & $\mathrm{SC}$ & $\mathrm{TC}$ & $\mathrm{SC}$ \\
\hline & 293 & 1.225 & -0.708 & -2.984 & 1.725 & & & & \\
\hline & 298 & 1.259 & -0.331 & -3.119 & 0.820 & & & & \\
\hline & 303 & 1.314 & -0.136 & -3.310 & 0.343 & & & & \\
\hline \multirow[t]{6}{*}{$\mathrm{Pb}$} & 288 & 1.901 & 0.535 & -4.552 & -1.281 & 5.535 & 46.556 & 34.963 & 166.180 \\
\hline & 293 & 1.904 & 0.782 & -4.638 & -1.906 & & & & \\
\hline & 298 & 1.992 & 1.224 & -4.936 & -3.032 & & & & \\
\hline & 303 & 2.021 & 1.66 & -5.092 & -4.196 & & & & \\
\hline & 308 & 2.033 & 1.876 & -5.207 & -4.805 & & & & \\
\hline & 313 & 2.076 & 1.957 & -5.402 & -5.092 & & & & \\
\hline
\end{tabular}


indicated that the adsorption of $\mathrm{Pb}$ had a higher spontaneity and larger feasibility, which was one of the reasons for the greater adsorption capacity of $\mathrm{Pb}$ than $\mathrm{Cd}$.

$\Delta H^{0}$ can indicate an energy barrier during adsorption, and $\Delta H^{0}>0$ suggests that adsorption is endothermic and the increase in temperature helps adsorption. ${ }^{24}$ That the $\Delta H^{0}$ of $\mathrm{Cd}$ and $\mathrm{Pb}$ adsorption on $\mathrm{TC}$ and $\mathrm{SC}$ was greater than zero suggested that (1) to obtain a larger adsorption capacity the hydrated metal ions should be dehydrated all or part of combined water to decrease diameter, which was an endothermic process, ${ }^{32,34}$ and (2) both the diffusion of $\mathrm{Cd}$ and $\mathrm{Pb}$ from the liquid phase to the solid one and the broken of ion bond for $\mathrm{Cd}$ and $\mathrm{Pb}$ ion exchange adsorption needed energy or thermo. $^{34,35}$ TC had a smaller $\Delta H^{0}$ than that of SC, so TC needed less energy to reach a same sorption capacity.

The values of $\Delta S^{0}$ more than zero in this study demonstrated the increase in the random of adsorption, which was probably due to (1) the structure change of carbons, $\mathrm{Cd}$, and $\mathrm{Pb}$ during adsorption, the replacement of water molecules on carbons by ions of $\mathrm{Cd}$ and $\mathrm{Pb}$, and the dehydration of $\mathrm{Cd}$ and $\mathrm{Pb}$ hydrated ions for diffusing into the micropores of carbons; $;^{33,36}(2)$ the release of $\mathrm{H}^{+}$ from carbon could also produce a positive value of $\Delta S^{0}$. Whereas $\Delta S^{0}$ less than zero reveals that the order of adsorption increased during adsorption. ${ }^{17}$ The $\Delta S^{0}$ of TC was less than that of SC, so the adsorption of $\mathrm{Cd}$ and $\mathrm{Pb}$ on TC was more ordered.

\subsection{Effect of sodium chloride and humic acid}

In practically, the adsorption of heavy metals by activated carbon can be affected by several environmental factors. In this study, $\mathrm{NaCl}$ and $\mathrm{HA}$ were used as competitive ion and dissolved organic compound, respectively. The adsorption of $\mathrm{Cd}$ and $\mathrm{Pb}$ on both TC and SC decreased with the increase in $\mathrm{NaCl}$ from 0.01 to $0.5 \mathrm{~mol} \mathrm{~L}^{-1}$ (Fig. 5e), but was positively affected by the existence of HA ranging from 5 to $5 \mathrm{mg} \mathrm{L}^{-1}$ (Fig. $5 \mathrm{f}$ ).

The decrease in adsorption of $\mathrm{Cd}$ and $\mathrm{Pb}$ by $\mathrm{NaCl}$ might be resulted from the changes in the properties of electrical double layer of adsorbent. According to the surface chemistry theory, ${ }^{37}$ when solid adsorbent is in contact with adsorbate species in solution, they are bound to be surrounded by an electrical diffused double layer, the thickness of which is significantly expanded by the presence of electrolyte. Such expansion inhibits the adsorbent particles and metal species from approaching each other more closely and leads to the lower adsorption through the weakened electrostatic attraction. The competition adsorption between $\mathrm{Na}^{+}$and ions of $\mathrm{Pb}$ and $\mathrm{Cd}$ for adsorption sites of TC or SC might also impair the adsorption of $\mathrm{Pb}$ and $\mathrm{Cd}$ on $\mathrm{TC}$ and SC. At low $\mathrm{pH}$ values, the negatively charged HA was easily adsorbed onto TC and SC, and the interaction of $\mathrm{Cd}$ and $\mathrm{Pb}$ ions with surface adsorbed $\mathrm{HA}$ on $\mathrm{TC}$ and SC was stronger than that of $\mathrm{Cd}$ and $\mathrm{Pb}$ with bare TC and SC. So, the presence of HA, a dissolved organic compound, in the environment could be a sink of $\mathrm{Cd}$ and $\mathrm{Pb}$ pollutants.

\subsection{Evaluation of adsorption isotherms}

Adsorption occurring in a solid-liquid system is a dynamical equilibrium process. Adsorption isotherm can demonstrate the distribution of adsorbate between solid and liquid phases at adsorption equilibrium, and offer a theoretic maximum adsorption capacity, which are of great significance for the optional design of adsorption device and the analysis of adsorption mechanism. The mostly used adsorption isotherm models of Langmuir and Freundlich were used in this study. The values of $R^{2}$ obtained from both Langmuir and Freundlich isotherms for TC and SC ranked from 0.98-0.99 and 0.96-0.99, respectively, revealing that both isothermal models could fit the data at adsorption equilibrium, especially the Langmuir model.

The parameters obtained from the slopes and intercepts of isotherms are presented in Table 4. The maximum adsorption capacity $Q_{\mathrm{m}}$ of $\mathrm{TC}$ for $\mathrm{Cd}$ and $\mathrm{Pb}$ adsorption was 48.08 and $61.73 \mathrm{mg} \mathrm{g}^{-1}$ and of SC was 40.98 and $58.82 \mathrm{mg} \mathrm{g}^{-1}$, respectively, at initial $\mathrm{pH}$ of 5 and $25{ }^{\circ} \mathrm{C}$ in the solution. These values were more than the figures reported in the study of Momčilovic et al. ${ }^{12}$ However, the $Q_{\mathrm{m}}$ of both carbons was lower than the $Q_{\mathrm{m}}$ values in the studies of Wang et al. ${ }^{10}$ and Xu et al. ${ }^{22}$ The $Q_{\mathrm{m}}$ of Cd on bean husk-based carbon activated by $\mathrm{HNO}_{3}$ (ref. 38) and the $Q_{\mathrm{m}}$ of $\mathrm{Pb}$ on lotus stalk carbon activated by $\mathrm{H}_{3} \mathrm{PO}_{4}$ (ref. 39) reached 180 and $139 \mathrm{mg} \mathrm{g}^{-1}$, respectively, which were far higher than the values of $Q_{\mathrm{m}}$ in the present study. Furthermore, the $Q_{\mathrm{m}}$ of TC and SC for Cd and $\mathrm{Pb}$ was less than 56.82 and $70.42 \mathrm{mg} \mathrm{g}^{-1}$ of the commercial activated carbon (Table 4 ). These different adsorption efficiencies were probably caused by different physicochemical properties of adsorbents due to different raw materials and methods for the preparation of activated carbons and adsorption parameters. Similar to the result in Youssef et al., ${ }^{3}$ TC and SC presented low specific surface areas but high values of $Q_{\mathrm{m}}$, indicating that surface functional groups and $\mathrm{pH}_{\mathrm{IEP}}$ of carbons played a key role in $\mathrm{Cd}$ and $\mathrm{Pb}$ adsorption. The phosphate-containing functions in TC and SC could also help improve the adsorption capacity.

$1 / n$ represents the curve of isotherm or the energy distribution of adsorption site. $1 / n<1$ indicates a more heterogeneous adsorption site and energy distribution and a feasible adsorption, and $2<n<10$ means an easier adsorption. ${ }^{14}$ The values of $1 / n$ in both carbons ranged between 0.1 and 0.5 in this work, indicating that the adsorption of both metal ions on both carbons could occur easily. $R_{\mathrm{L}}$ values based on Langmuir isotherm can also be used to assess the difficulty of adsorption. Adsorption is unfavorable, linear, favorable, or irreversible when $R_{\mathrm{L}}>0, R_{\mathrm{L}}=1,0<R_{\mathrm{L}}<1$, or $R_{\mathrm{L}}=0$, respectively. ${ }^{40}$ The values of $R_{\mathrm{L}}$ ranging from 0 to 1 meant that the adsorption was favorable in the present study.

Comparatively, TC possessed a better adsorption ability for both ions than SC, and the adsorption capacity of $\mathrm{Pb}$ was larger than that of $\mathrm{Cd}$ on both carbons. TC had a smaller $\mathrm{pH}_{\mathrm{IEP}}$ compared to SC, and thus more negative charges at the same low initial solution $\mathrm{pH}$, which helped more with electrostatic attraction and complexing adsorptions. Similar to the results in Shi et al. ${ }^{24}$ the $Q_{\mathrm{m}}$ of $\mathrm{Pb}$ was obviously greater than that of $\mathrm{Cd}$, indicating a better affinity of $\mathrm{Pb}$ on both carbons. There were three reasons: (1) the free energy and diameter of hydrated ions are main factors in determining adsorption capacity. Hydrated ions with smaller diameters can easily diffuse inside carbon particles. Ions with low and high hydrated energy tend to be combined with carbon and water, respectively; so inside carbon 
Table 4 Langmuir and Freundlich parameters of $\mathrm{Cd}$ and $\mathrm{Pb}$ adsorption on Typha angustifolia activated carbon (TC), Salix matsudana activated carbon (SC), and commercial activated carbon (CAC)

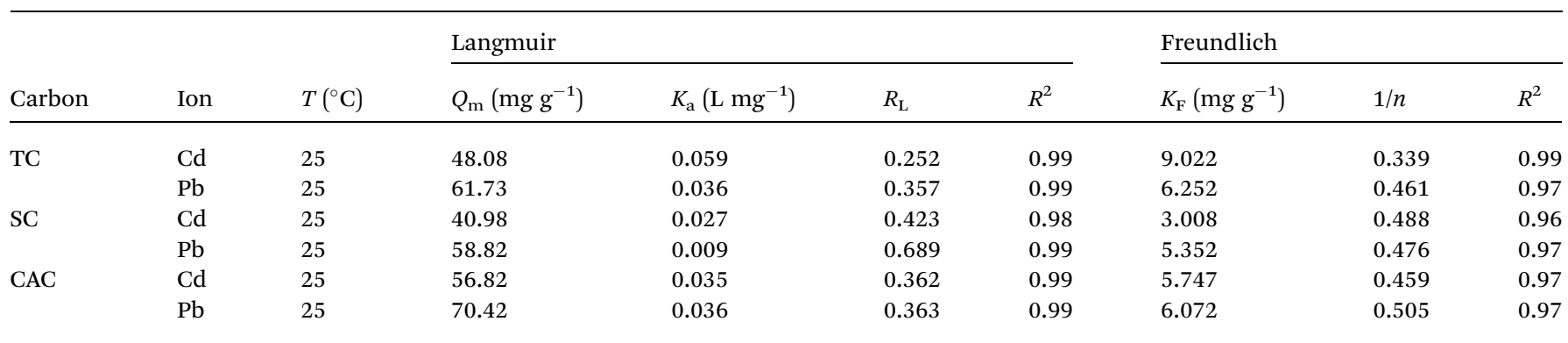

particulates, ions with low hydrated energy are easy to dehydrate, and thus adsorbed inside carbons. Therefore, the $Q_{\mathrm{m}}$ of $\mathrm{Pb}$ was more than that of $\mathrm{Cd}$ due to a lower diameter (the diameter of hydrated ions of $\mathrm{Cd} 4.26 \AA$, $\mathrm{Pb} 4.01 \AA)$ and free energy of hydrated ion of $\mathrm{Pb}^{32}$ (2) Metal ions with a large diameter tend to be electrostatically adsorbed, so hydroxy metal ions are more easily adsorbed compared to free metal ions. The hydrolysis constant of $\mathrm{p} K_{1}$ of $\mathrm{Pb}$ is 7.9 less than 10.1 of $\mathrm{Cd}$, indicating $\mathrm{Pb}$ could be easily hydrolyzed, and thus was readily adsorbed by electrostatic attraction. ${ }^{41}$ (3) Metal with a larger electric negativity can easily receive electrons and vice versa. The electric negativity of $\mathrm{Pb}$ is 2.33 more than 1.69 of $\mathrm{Cd}$, which was also one of the reasons for higher $Q_{\mathrm{m}}$ of $\mathrm{Pb}$; furthermore, the greater the electric negativity of metals, the more acidity there is, so $\mathrm{Pb}$ tended to combine with hydroxyl radical, carboxyl, and phosphate groups on activated carbons surface according to the theory of hard and soft acid and base. ${ }^{42}$

\subsection{Adsorption mechanism and types}

In this study, all the values of $R^{2}$ obtained from intraparticle diffusion equation were more than $0.96 \%$, indicating that the intraparticle diffusion was a rate-limiting step in adsorption. However, if intraparticle diffusion is the only rate-controlling process, the fitted curve will start from the origin; if film diffusion and intraparticle diffusion occur independently, there should be two or more fitted lines, the first one representing boundary diffusion, and the second one representing intraparticle diffusion. ${ }^{43}$ In the present research, there was only one fitted line which did not start at the origin (Fig. 6); moreover, the values of $R^{2}$ obtained from the film diffusion model were less than 0.85 (data not provided in this paper), suggesting that both film and intraparticle diffusions occurred simultaneously, but intraparticle diffusion was the main rate control step; similar results were presented in studies of Youssef $e t ~ a l .{ }^{3}$ and Xu and Liu. ${ }^{22}$ Research also showed that the formation of a chemical bond was also a rate control process. ${ }^{44}$ The values of $R^{2}$ resulted from the pseudo-second order model were 0.99 in this experiment, revealing that chemical reaction played an important role during adsorption of $\mathrm{Cd}$ and $\mathrm{Pb}$ on TC and SC, and was also a rate limiting step. ${ }^{22}$

$\Delta G^{0}, \Delta H^{0}$, and $\Delta S^{0}$ also provide a way to judge adsorption mechanism. $\Delta G^{0}<0$ reveals that adsorption process is controlled by the change of entropy not enthalpy; $\Delta G^{0}>$ 0 indicates a common phenomenon of ion exchange adsorption, the formation of metal ion complexing compound on adsorptive sites of adsorbent. ${ }^{44} \Delta H^{0}>0$ shows there is a chemical or bonding reaction, and $\Delta S^{0}>-10^{-12} \mathrm{~kJ} \mathrm{~K}^{-1}$ $\mathrm{mol}^{-1}$ means there is a dissociation or deprotonation during adsorption. ${ }^{24}$ In the present study, most $\Delta G^{0}<0$ suggested that the change of entropy controlled the adsorption process; for SC, a small part of $\Delta G^{0}>0$ referred to that ion exchange occurred during the adsorption of Cd on SC; $\Delta H^{0}>0$ and $\Delta S^{0}>$ 0 indicated that the adsorption contained chemical reaction and dissociation, respectively. Furthermore, the $R^{2}$ values from isothermal models ranged from 0.96 to 0.99 , suggesting that there were both single molecular layer chemical reactions and multiple molecular layer physical reactions during adsorption. ${ }^{45}$

After the adsorption of $\mathrm{Cd}$ and $\mathrm{Pb}$, the appearance of some new peaks at $530.31 \mathrm{eV}(\mathrm{C}=\mathrm{O}), 533.93,534.47 \mathrm{eV}(-\mathrm{COOH})$ (Fig. 4 TC-f), $532.43 \mathrm{eV}$ (C-OH), and $533.14 \mathrm{eV}$ (C-O-C) (Fig. 4
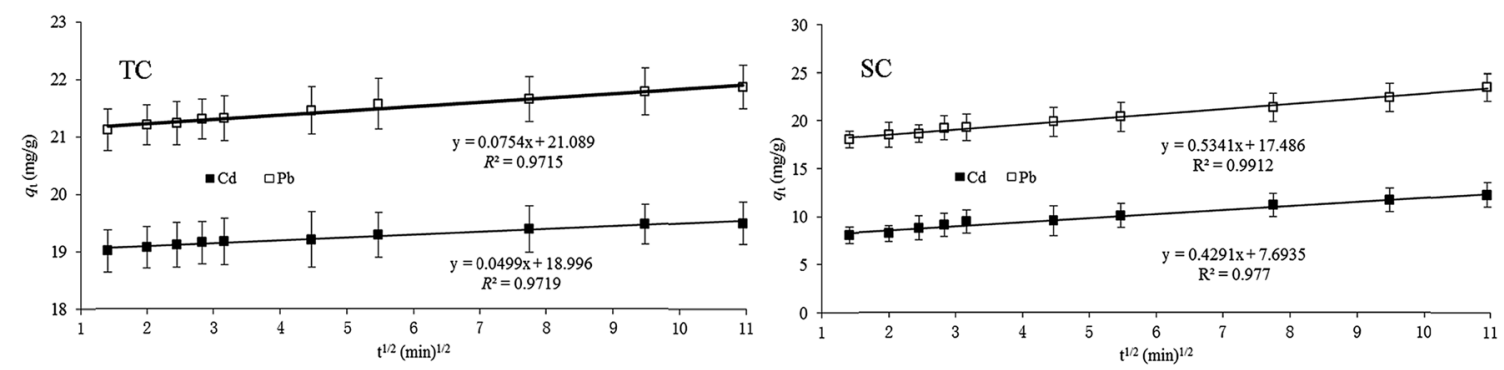

Fig. 6 Intraparticle diffusion model of $\mathrm{Cd}$ and $\mathrm{Pb}$ adsorption on Typha angustifolia activated carbon (TC) and Salix matsudana activated carbon (SC). Error bar is the standard deviation of the mean. 
Table 5 Four cycles of $\mathrm{Pb}$ and $\mathrm{Cd}$ adsorption and desorption on Typha angustifolia activated carbon (TC) and Salix matsudana activated carbon (SC)

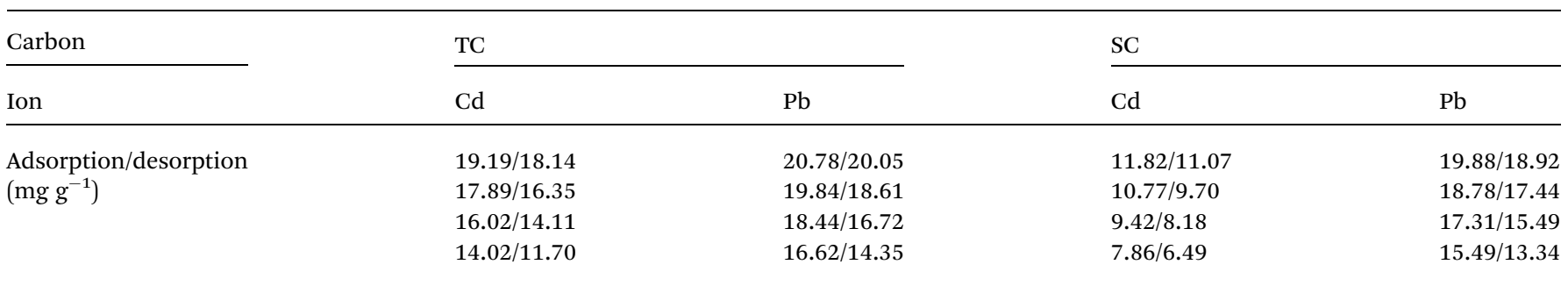

SC-f), the disappearance of peak at $536.53 \mathrm{eV}$ (Fig. 4 SC-e), and the shift of some peaks assigned to groups containing $\mathrm{O}$ further suggested the occurrence of chemical reactions between TC and $\mathrm{SC}$ with $\mathrm{Cd}$ and $\mathrm{Pb}$.

\subsection{Adsorption and desorption cycle}

Desorption studies of metals are helpful for the recycling of adsorbents and the recovery of metal resources. The results of the multiple adsorption/desorption cyclic tests are presented in Table 5. The adsorption capacity of $\mathrm{TC}$ for $\mathrm{Cd}$ and $\mathrm{Pb}$ was reduced by 27.94 and $20.2 \%$ from 19.19 to $14.2 \mathrm{mg} \mathrm{g}^{-1}$ and 20.78 to $16.62 \mathrm{mg} \mathrm{g}^{-1}$, respectively. While for SC, it declined by 33.50 and $22.08 \%$, respectively. Thus, it was feasible for the recovery of $\mathrm{Pb}$ and $\mathrm{Cd}$ and the regeneration of TC and SC after adsorption equilibrium, which would effectively reduce the overall cost for the adsorbents. The reason for the small fraction of heavy metal ions adsorbed by TC and SC not recoverable by desorption was probably that the metal ions were bound to the TC and SC through strong interaction, and thus desorption capacity reduced during successive cycles. For the more precision reason of desorption, further study is required to know whether $\mathrm{HCl}$ provides an ability to change the structure of the adsorbent.

\section{Conclusions}

The adsorption efficiency relied positively on the $\mathrm{pH}$ and humic acid but negatively on $\mathrm{NaCl}$ in the media. $\mathrm{Cd}$ and $\mathrm{Pb}$ adsorption from solution was spontaneous and endothermic and contained physico-chemical reactions. The intra-particle diffusion and chemical reaction were the adsorption rate control steps. The pseudo second order and Langmuir models fitted the adsorption process very well. The $Q_{\mathrm{m}}$ of Cd and $\mathrm{Pb}$ was 48.08 and $61.73 \mathrm{mg} \mathrm{g}^{-1}$ on $\mathrm{TC}$ and 40.98 and $58.82 \mathrm{mg} \mathrm{g}^{-1}$ on $\mathrm{SC}$, respectively. Both activated carbons provided good regenerating and reusing properties. The results indicated that both TC and SC were potential adsorbents for $\mathrm{Cd}$ and $\mathrm{Pb}$ from aqueous solution. Yet, further researches are required to optimize the preparation and maximize the adsorption capacity.

\section{Acknowledgements}

This work was funded by the Project of Education Department of Hunan Province of China (Grant No. 16A221) and the
National Natural Science Foundation of China (Grant No. 51579097). We are thankful to the Editors and Referees for their precious comments on our manuscript.

\section{References}

1 R. A. Goyer, Environ. Health. Perspect., 1993, 100, 177-187.

2 G. Van Maele-Fabry, N. Lombaert and D. Lison, Environ. Int., 2016, 86, 1-13.

3 A. M. Youssef, T. El-Nabarawy and S. E. Samra, Colloids Surf., A, 2004, 235, 153-163.

4 Z. Li, B. Huang, J. Huang, G. Chen, C. Zhang, X. Nie and G. Zeng, RSC Adv., 2015, 5, 90588-90595.

5 G. Issabayeva, M. K. Aroua and N. M. N. Sulaiman, Bioresour. Technol., 2006, 97, 2350-2355.

6 I. Ghodbane, L. Nouri, O. Hamdaoui and M. Chiha, J. Hazard. Mater., 2008, 152, 148-158.

7 F. Bouhamed, Z. Elouear and J. Bouzid, J. Taiwan Inst. Chem. Eng., 2012, 43, 741-749.

8 M. A. P. Cechinel and A. A. U. D. Souza, J. Cleaner Prod., 2014, 65, 342-349.

9 C. K. Singh, J. N. Sahu, K. K. Mahalik, C. R. Mohanty and B. R. Mohan, J. Hazard. Mater., 2008, 153, 221-228.

10 L. Wang, J. Zhang, R. Zhao, Y. Li and C. Li, Bioresour. Technol., 2010, 101, 5808-5814.

11 K. Q. Li, Z. Zheng and Y. Li, J. Hazard. Mater., 2010, 181, 440447.

12 M. Momčilović, M. Purenović, A. Bojić, A. Zarubica and M. Ranđelović, Desalination, 2011, 276, 53-59.

13 A. M. Bahri, L. Calvo, M. A. Gilarranz and J. J. Rodriguez, Biochem. Eng. J., 2012, 203, 348-356.

14 M. Maddisona, T. Mauring, K. Remm, M. Lesta and U. Mander, Ecol. Eng., 2009, 35, 258-264.

15 L. Ren, J. Zhang, Y. Li and C. Zhang, Biochem. Eng. J., 2011, 168, 553-561.

16 G. Berndes, F. Fredrikson and P. Börjesson, Agric., Ecosyst. Environ., 2004, 103, 207-223.

17 M. A. Z. Abidin, A. A. Jalil, S. Triwahyono, S. H. Adam and N. H. N. Kamarudin, Biochem. Eng. J., 2011, 54, 124-131.

18 V. K. Gupta and A. Nayak, Biochem. Eng. J., 2012, 180, 81-90. 19 S. Orsetti, M. D. L. M. Quiroga and E. M. Andrade, Chemosphere, 2006, 65, 2313-2321.

20 Y. Li, Q. Yue and B. Gao, J. Hazard. Mater., 2010, 178, 455-461. 21 M. Li, Y. Liu, G. Zeng, S. Liu, X. Hu, D. Shu, L. Jiang, X. Tan, X. Cai and Z. Yan, J. Colloid Interface Sci., 2017, 485, 269-279. 
22 T. Xu and X. Liu, Chin. J. Chem. Eng., 2008, 16, 401-406.

23 D. Doulia, C. Leodopoulos, K. Gimouhopoulos and F. Rigas, J. Colloid Interface Sci., 2009, 340, 131-141.

24 T. Shi, S. Jia, Y. Chen, Y. M. Wen and C. Du, J. Hazard. Mater., 2009, 169, 838-846.

25 Y. S. Ho, G. McKay, D. A. J. Wase and C. F. Forster, Adsorpt. Sci. Technol., 2000, 18, 639-650.

26 A. M. B. Hamissa, A. Lodi, M. Seffen, E. Finocchio and R. Botter, Biochem. Eng. J., 2010, 159, 67-74.

27 B. I. Olu-Owolabi and E. I. Unuabonah, Appl. Clay Sci., 2011, 51, 170-173.

28 L. D. Pablo, M. L. Chávez and M. Abatal, Biochem. Eng. J., 2011, 171, 1276-1286.

29 W. S. W. Ngah, L. C. Teong, R. H. Toh and M. A. K. M. Hanafiah, Biochem. Eng. J., 2013, 223, 231-238.

30 A. Örnek, M. Özacar and İ. A. Şengil, Biochem. Eng. J., 2007, 37, 192-200.

31 D. Mohan, C. U. Pittman, M. Bricka, F. Smith and B. Yancey, J. Colloid Interface Sci., 2007, 310, 57-73.

32 E. R. Nightingale, J. Phys. Chem., 1959, 63, 1381-1387.

33 E. Eren, J. Hazard. Mater., 2009, 165, 63-70.
34 X. L. Wu, D. Zhao and S. T. Yang, Desalination, 2011, 269, 8491.

35 T. S. Anirudhan and P. S. Suchithra, J. Ind. Eng. Chem., 2010, 16, 130-139.

36 X. Li, Y. Li and Z. Ye, Biochem. Eng. J., 2011, 178, 60-68.

37 L. Osipow, Soil Chemical: Theory and Industrial Applications, Krieger, NewYork, 1972.

38 L. Chávez-Guerrero, R. Rangel-Méndez, E. Muñoz-Sandoval, D. A. Cullen, D. J. Smith, H. Terrones and M. Terrones, Water Res., 2008, 42, 3473-3479.

39 H. Liu, P. Dai, J. Zhang, C. Zhang, N. Bao, C. Cheng and L. Ren, Chem. Eng. J., 2013, 228, 425-434.

40 T. Depci, A. R. Kul and Y. Önal, Biochem. Eng. J., 2012, 200, 224-236.

41 D. S. Lin, Y. M. Xu, G. H. Sun and X. H. Dai, J. Agro-Environ. Sci., 2007, 26, 510-515.

42 Z. T. Zhou, J. Agro-Environ. Sci., 1981, 2, 68-73.

43 Y. S. Ho, Water Res., 2003, 372, 323-2330.

44 T. S. Anirudhan, P. S. Suchithra and S. Rijith, Colloids Surf., A, 2008, 326, 147-156.

45 T. Karthikeyan, S. Rajgopal and L. R. Miranda, J. Hazard. Mater., 2005, 124, 192-199. 